Charles Le Guintrec, romancier, poète, critique, est né à Plescop dans le Morbihan. Il est l'auteur de plus de dix romans, dont La Ville en loques et Le Christ aux orties, tous parus chez Albin Michel. Chez ce même éditeur, il y a aussi deux volumes des ses oeuvres poétiques complètes, La Lumière et l'Argile (1945-1970) et Le Règne et le Royaume (1970-1983), et son dernier recueil La Source et le Secret (1990). "Je rêve d'une poèsie à l'usage de l'homme. Je rêve d'un chant qui pourrait être repris par tout un peuple. Je rêve de ces mots très simples, très lisses, qui étaient ceux des premiers hommes qui, eux, n'avalent besoin de rien d'autre pour glorifier la vie que d'eau, de pain, de lait et de lumière."

\title{
$\$$
}

Solitude

Dans cette vieille auberge à l'ombre des tilleuls Je m'invite à plaisir le soir quand je suis seul Que j'écoute la givre et regarde l'abeille Qui butine de l'or dans l'argent de la treille.

Je crois avoir perdu l'amour des jeunes filles Qui s'en vont à la mer des garçons à leurs bras Elles rient de n'aimer que des galants courtois Et plongent demi-nues entre flots et flotilles.

Je crois avoir perdu de ma jeunesse folle Les vertues qui faisaient sourire mes amis Que sont-ils devenus? Sont-ils jamais partis? Je les aimais pour leur arrogance d'école.

Verlaine nous était mentor

Le brûle-gueule

De sa bouche donnait du verbe à sa chanson En ce temps-là j'étais candide et tendre quand Je me voulais le soir triste à mourir et seul. 


\section{Art poétique}

à Pierre Michel

Que m'emportent ces gens que font des vers avec Les secrètes fumées, les drogues éphémères Je chante pour aimer le pays de mes pères Pour effleurer la harpe et jouer du rebec. Qui m'a vu dans un livre entre rêve et rivière Reconnait de mes yeux la perçante droiture Le verbe est dans le fruit le sang est nourriture Le figuier n'est jamais stérile quand j'espère.

Je reprends de mes jours l'ardente litanie De mes nuits folles les déraisons me reviennent Je laisse les rébus aux faiseurs de phalènes Et l'hermétisme à ceux qui n'ont pas de folie.

Si j'aime dans le ciel, si je marche sur l'eau Si le chant des oiseaux me rapproche des anges C'est que j'at célébré jusque dans la souffrance Celui-là qui nous vient avec du vin nouveau. 